\title{
When you only have a week Rapid-response, grassroots public services for access, wellness, and student success
}

$\mathbf{T}$ he cascade of events following the global outbreak of COVID-19 produced exceptional examples of camaraderie, collaboration, and resourcefulness. In this article, we share two ways UCLA Library public services staff came together to rapidly re-envision learner-centered library services and support in response to the COVID-19 campus shutdown. In both cases, library staff adapted existing services (e.g., workshop delivery and tutorial design) to embrace remote technologies and scale to meet the needs of a greater number of learners.

As students, staff, faculty, and librarians dispersed to their respective locales of isolation, a host of new information needs arose. At UCLA, in-person meetings were an established norm, despite staff offices being dispersed across a sprawling campus. Many librarians and staff members were already set up with access to collaborative software such as Slack, Confluence, and Asana. However, there was uneven adoption, and use of those platforms was already linked to overall comfort levels with technology.

Staff and lecturer ease with technology was an initial focus point for the larger institution, evidenced by preliminary campus-wide efforts to initiate staff and lecturers to Zoom and webbased teaching tools. Campus efforts focused on preparing lecturers for the coming quarter by providing technical support and transitional instructional design. Librarians hustled to the backend and immediately began purchasing electronic versions of course reserve material--a deviation from our previous print-only policy for textbooks. There was a tremendous emphasis on electronic material acquisition, both through our existing vendors and through newly opened platforms such as the National Emergency Library (NEL) and Hathi Trust.

Librarians quickly noticed gaps in the approach. First, most of the newly unlocked titles on these large platforms (NEL, Hathi- Trust) would not be used by first and second-year undergraduates. Most deep cuts are for upperlevel research. Additionally, simply announcing access is insufficient for students unfamiliar with navigating library websites or catalogs for resources.

Data informing undergraduate information needs were provided by the campus first-year experience office following a quick poll of 50 primarily first-generation and transfer students. The office shared library-relevant responses, including anxiety surrounding Internet access, study spaces, social learning experiences, and technological adaptations. These anxieties were in line with library-sponsored surveys from earlier years, which indicated that undergraduates principally want access to course reserves

M. Wynn Tranfield is librarian, email: wynntranfield@ library.ucla.edu, Doug Worsham is librarian, email: dworsham@library.ucla.edu, and Nisha Mody is lead for teaching and learning, email: nmody@library.ucla. edu, at the UCLA Library

(c) 2020 M. Wynn Tranfield, Doug Worsham, and Nisha Mody 
and a physical place to study-whether it be quiet or conducive for group work. These responses track with previous surveys of student library use. Since the library could no longer provide that physical safe space for learning, we considered ways to reach out with concrete acknowledgements and ideas for workarounds.

\section{Remote Control live-streamed workshops}

On March 26, ten days after UCLA Library staff began working from home and less than a week after almost the entire campus vacated their learning spaces, offices, and campus housing, UCLA Library and other campus partners managed to build an impressive corpus of resources targeting faculty members in the process of moving their courses to a remote environment. Topics included how to optimize technology, build assignments and exams, and promote remote discussions.

There was, however, no equivalent "adjustment orientation" for students, many of whom now found themselves in suboptimal learning environments without the support infrastructure provided by a highly residential campus. In addition to research support provided by the library, students relied on the physical space for web access, computers, conducive study environments, and programming. Many students also found themselves lacking community since they were back in their home environments or perhaps more isolated in other spaces.

To address this gap, Wynn Tranfield suggested we create Remote Control, a series of webinars aimed at helping students find tools they can use to adjust to their new remote learning environment. ${ }^{1}$ Learning objectives covered time management strategies and tips for setting boundaries with housemates to tips for communicating with professors, teaching assistants, and peers. We also provided comprehensive coverage of tools for finding course materials, software demonstrations, and strategies for handling an increase in reading assignments. These webinars were designed to empower students to use tools introduced to them and provide an affirming environment--one that supported and acknowledged that their learning would look and feel very different from the previous quarter. All webinars included segments on wellness, recognizing that this was an unprecedented and stressful time to learn.

With less than a week to prepare for the new quarter, the Remote Control workshops were created, promoted, and livestreamed. There was extensive collaboration before, during, and after the webinar with teaching librarians, the Teaching and Learning Team, and support staff to manage content, tech, streaming, and promotional logistics. The webinars were all very well attended, and feedback from students was resoundingly positive. All webinars were recorded and made available along with the slides and relevant links.

\section{Remote access video tutorials}

On April 10, Nisha Mody, UCLA Library's team lead for teaching and learning, posted a question to one of the library's organizational Slack channels, asking if it would be possible for someone to create a screencast on installing VPN/Proxy. As a result 
of a rapid transition to remote instruction, UCLA's approximately 75,000 students, staff, and faculty members had suddenly found themselves learning, teaching, and conducting research from off-campus. The importance of off-campus access to library resources, always a key issue, had suddenly become an urgent one. Email questions and instructor requests for help with remote access were skyrocketing, and staff in multiple units reported that the standard documentation was not working for all users. There was definitely a need for something more visual and engaging, but as the campus neared the midpoint of a very unusual academic quarter, there was little time available to make it happen.

The library was fortunate to have WI+RE (Writing Instruction + Research Education), ${ }^{2}$ an experienced learnercentered design team that was already familiar with collaborating across units and creating open educational resources. That said, WI+RE's previous projects had been completed on 8-12 week

$1 ?$ Initial question:

Empathy map: What are the key challenges and breakthroughs? 2 () Learning outcomes: What will

Key idea: Create learner-narratives focused on concepts.

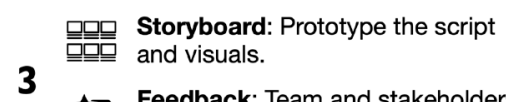

Feedback: Team and stakeholders review and revise prototypes.

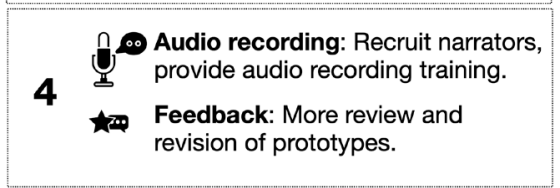

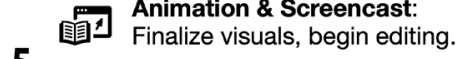 \\ 5 \\ Check-in: Final stakeholder check- in. Ready to go?}

$6 \begin{aligned} & \text { Caption \& Publish! } 3 \text { videos } \\ & \text { captioned and published! }\end{aligned}$

The six-day grassroots media production timeline. a breakthrough by presenting the videos as learner and researcher narratives. The primary goals became increasing awareness of the value and purpose of remote access, building a conceptual understanding of the process, and improving confidence through first-person narratives from a diverse group of learners and researchers.

With the challenges and learning outcomes defined, the team launched a round of scriptwriting and rapid prototyping. The prototypes developed quickly, with 14 staff from four library units, including four library student employees, providing feedback and refining the writing and visual design. Staff mobilized to provide quick cross-trainings on audio recording and editing, and within six days of the initial request, the first three videos in the series (covering VPN and Proxy on a Mac OS and Proxy on Windows) were captioned and posted to YouTube and shared with departments and programs across campus. ${ }^{4}$

It was a busy week, full of extensive collaboration. For some, it was the first time they had been directly involved in a media production project. And for everyone involved, coming together to prioritize the 
library's response involved high levels of trust, extensive collaboration and communication, and working at a pace that would have seemed impossible just weeks before. Subsequent projects built on the success of this grassroots effort. Within a month, the team added two new videos to the series, one on remote access for Chromebook users and a fourth providing an overview of the many options for off-campus eBook access. ${ }^{5}$ In all, this collection of remote access videos was viewed more than 2,400 times so far on YouTube and Twitter, incorporated into library research guides, and shared widely across academic departments.

\section{Conclusion}

Starting something new in the librarywhether it be a program, collection, resource, or workshop-can be challenging. How the library as a whole responds to new ideas has not always been compassionate, flexible, or understanding. As we reflected on the team's processes, we marveled at the speed of accomplishments. When done remotely, previous boundaries and hierarchical workflows that slowed creativity and collaboration were nonexistent. The attitude was, if you can do it, do it, and if you need help, please ask. This supported teamwork across units and expanded opportunities for the involvement of student employees. For students, the experience provided a way to expand their positions beyond support for staff and librarians. According to one:

For most students, the realm of opportunities for work experience available to us are always framed as student experiences. From on-campus jobs to research positions to fancy internships, there is always some expectation that our successes and failures are qualified by our status as "just students." This isn't the case for learner-centered design. Collaborating with professional staff and feeling like a valuable, co-equal contributor gives new meaning to the work. I felt much more confident sharing my ideas, and I think having that level playing field made me more open to constructive feedback because I felt like I was being approached as a respected colleague, not a naive student.-Michael Lima-Sabatini, Powell Library inquiry specialist

When you only have a week, perceptions about what can be done can shift, encouraging an agile approach and collaboration, even during isolation. With compassion and flexibility, team members had an opportunity to highlight their skills in a rapidly moving environment. Student employees, especially, were critical to the success of these projects. The UCLA Library is proud that we were to complete these initiatives, retaining our values of being learner-centered, accessible, and diverse-representing student needs throughout the country, and world. We hope these initiatives will inspire future grassroots collaboration within and outside the library, leveraging our existing organization and resources. Regardless of the mode in which students learn and instructors teach, it is possible to come together and reshape existing structures for the greater good of our learning community.

\section{Acknowledgements}

The authors are particularly grateful for the partnership and collaboration of the many people who contributed to these projects, including Michael Lima-Sabatini, Salma Abumeeiz, Zoe Borovsky, Nadia Brooks, Kathy Brown, Matt Johnson, Suzy Lee, Scott Martin, Sylvia Page, Kate Pham, Kian Ravaei, Renee Romero, Natalie Selzer, and Hannah Sutherland.

\section{Notes}

1. Wynn Tranfield, "Research Guides: Remote Control Webinar Series: Remote Control Series," accessed May 19, 2020, https:// guides.library.ucla.edu/remotecontrol/series.

(continues on page 336) 
event or if it is something that will stay with us in repeated surges.

A key point here, and a key point in all planning, is that we don't know. We have to make estimations based on the best information we have and alter our plans as new information arises. I don't know that any of us or our libraries were prepared for a pandemic of this scale. However, that doesn't mean that this type of scenario was not thought about by others outside of the library world. In the most recent Worldwide Threat Assessment delivered by the Director of National Intelligence to the Senate Select Committee on Intelligence, a flu-like pandemic is mentioned as a substantial threat to the United States. ${ }^{1}$ In terms of planning for the future of library collections, one would do well to consider the rest of this report. In fact, the first type of threat mentioned is cyberattacks. There are mentions of state actors being able to disrupt critical infrastructure in the United States for days to weeks. The report specifically mentions gas lines, but it is very easy to imagine these being attacks on the power grid or our cyber-infrastructure. How will our users access their research materials when the lights are out for a few weeks? It seems farfetched, but it seemed unthinkable a few months ago that most of the nation would be in self-isolation for public health reasons. Given that, we need to remember that print resources remain a valuable part of our arsenal, and we need to make certain that it remains a healthy part of our collections not just for crises, but for daily use. Print resources circulated before the crisis, and there isn't any evidence yet to think that activity will change. Library planners need to remember that while change is coming, the change may not be what we expect.

When the post-COVID-19 era arrives, I urge library leaders to adopt flexible, forwardlooking strategic and tactical plans for providing resources and services to our users. Above I use collections as an example, but this applies to every facet of library operations. What worked at the height of the COVID-19 crisis will likely not be the best solution for normal times or for future crises. Learn the library lessons from this pandemic, but don't let them lead you. Don't let COVID-19 make you build a Maginot Line for your library. Don't fight the last war.

\section{Note}

1. Daniel R. Coats, "Worldwide Threat Assessment of the US Intelligence Community," Statement for the Record to the Senate Select Committee on Intelligence, January 29, 2020, accessed May 5, 2020, https:// www.dni.gov/files/ODNI/documents/2019 -ATA-SFR---SSCI.pdf. $\approx$

("When you only have a week, " continues from page 329)

2. UCLA Library WI+RE. "About WI+RE." Page, WI+RE - Quick and practical research and writing tutorials, collaboratively designed by students at UCLA, 2020, https://uclalibrary. github.io/research-tips/about/.

3. Dani Brecher Cook and Doug Worsham, "Let's Build Something (The Toolkit)," April 2018, https://ucla.app.box.com/v/build -something-toolkit.

4. Doug Worsham, Nadia Brooks, Michael Lima-Sabatini, Kate Pham, Natalie Selzer, Kian Ravaei, Hannah Sutherland, Zoe Borovsky, Scott Martin, and Sylvia Page, "Remote Access_ _ Get Config- ured with VPN or Proxy on Mac, Windows, and Chromebook Computers," tutorial, UCLA WI+RE, May 2020, https://uclalibrary.github.io/research-tips /get-configured/.

5. Doug Worsham, Chris Lopez, Sylvia Page, Matthew Johnson, Kian Ravaei, Katherine Ramirez, and Michael Lima-Sabatini, "Your Remote EBook Roadmap," tutorial, WI+RE-Quick and practical research and writing tutorials, collaboratively designed by students at UCLA, May 13, 2020, https://uclalibrary.github.io/research-tips /ebook-access/. $\boldsymbol{n}$ 